\title{
The Relation between Exposure to Environmental Tobacco Smoke and the Quantity of Cotinine in the Urine of School Children in Taif City, Saudi Arabia
}

\author{
Dalia El Sayed Desouky ${ }^{1,2 *}$, Gamal Elnemr ${ }^{3,4}$, Ali Alnawawy ${ }^{1,5}$, Azza Ali Taha ${ }^{1,2}$
}

\begin{abstract}
Environmental tobacco smoke (ETS) is a major public health problem for all ages. Despite the high prevalence of smoking among the Saudi population, there is limited information about levels of urinary cotinine in Saudi children exposed to SHS. The aim of the study was to assess the exposure of schoolchildren to ETS, and measure their urinary cotinine levels. Multistage cluster sampling was carried out, where schoolchildren from 4 schools were randomly chosen from primary schools in Taif city. A questionnaire including questions on SHS exposure and smoking rules in the residence were sent to students parents/guardians. Urine samples were taken and analyzed for total cotinine using chemiluminescent immunoassay. Of the studied children, $38.4 \%$ had a smoking father, $61.8 \%, 41.2 \%$ and $49.3 \%$ of them were exposed to ETS indoors, outdoors and both indoors and outdoors respectively. The mean urinary cotinine was significantly higher among children exposed to ETS compared to unexposed children. Urinary cotinine levels in children with both indoor and outdoor exposure was significantly higher compared with its level in children with single exposure. A significant positive correlation was found between urinary cotinine concentrations and the number of cigarette packs smoked by parents, and the number of smokers in the residence. The mean urinary cotinine level was significantly higher in children who reported no smoking rules at the residence.. The study revealed a high exposure of Saudi children to ETS. An antismoking media awareness campaign on the harmful effects of ETS should be carried out, in addition to family counseling programs targeted to parents to protect their children from ETS.
\end{abstract}

Keywords: Environmental tobacco smoke - urinary cotinine - School children - Taif - Saudi Arabia

Asian Pac J Cancer Prev, 17 (1), 139-145

\section{Introduction}

Environmental Tobacco Smoke (ETS) is also referred to as Secondhand Smoke (SHS), is the smoke burnt at the end of a cigarette, pipe, or cigar, in addition to the smoke exhaled out of the smoker's lungs (CDC, 2015). It is now considered more toxic than directly-inhaled firsthand smoke (FHS) (U.S. Food and Drug Administration, 2012). A passive smoker can be classified as someone living or working with a smoker (Salim et al., 2011). According to the Global Youth Tobacco Survey, about 50\% of world's children are exposed to (SHS) (Lando et al., 2010). Children are more vulnerable to the health effects of SHS (Martins-Green et al., 2014). This could be attributed to the sensitivity of their developing respiratory tract to environmental pollutants, the inhalation of more air per body volume compared to adults, the higher breathing frequency, and their inability to avoid SHS exposure as they have no free choice with respect to their environment
(Öberg et al., 2010). In addition, children often sit closer to their parents, family members, or caregivers making them closer to the source of pollutants than other passive smokers (Abou El-Ellaa et al., 2014).

Previous studies revealed that exposure to SHS during childhood increase the risk of respiratory disorders, middle ear disease (Tutka et al., 2002), dental caries (Shenkin et al., 2004), and the risk of developing lung cancer in adulthood (Vineis et al., 2005). Assessing specific smoke constituents or their metabolites in body liquids can give a precise data about exposure to SHS (Stošić et al., 2006). Cotinine is a biomarker of SHS exposure which is the major metabolite of nicotine (U.S. Department of Health and Human Services, 2006). It is found in blood, saliva and urine after exposure to nicotine (11), and its urinary levels are elevated in second hand smokers (Bernert et al., 2010). Cotinine can be measured with adequate sensitivity to assess SHS exposure (Goniewicz et al., 2011).

Studies have shown a strong dose- response relation

${ }^{1}$ Departments of Public Health and Community Medicine, College of Medicine and Applied Medical Sciences, ${ }^{3}$ Department of Internal Medicine, Faculty of Medicine, Taif University, Saudi Arabia, ${ }^{2}$ Department of Public Health and Community Medicine, Faculty of Medicine, Menoufyia University, ${ }^{4}$ Department of Medical and Radiological Research, Nuclear Materials Authority, ${ }^{5}$ Department of Public Health and Community Medicine, Faculty of Medicine (Damietta), Al-Azhar University, Egypt *For correspondence: dalia_desouky@yahoo.com 
between cotinine concentrations in non-smokers and the smoking behaviour of their partners (Goniewicz et al., 2011; Thomas et al., 2011; Abou El-Ellaa et al., 2014), especially at homes with no smoking restrictions (Thomas et al., 2011).

In the kingdom of Saudi Arabia (KSA), a latest country survey showed that the prevalence of tobacco use among males and females was $24 \%$ and $1 \%$ respectively (WHO, 2011). Thirty four studies published between 1987 and 2008 showed a total prevalence of (4.5-52.9\%) of current smoking (Bassiony et al., 2009). And according to the WHO country profile of Saudi Arabia in 2013, the current tobacco use was estimated to be $21.2 \%$ and $9.1 \%$ among male and female youth, compared to $35 \%$ and $5.7 \%$ among adult males and females (WHO, 2013). In a study to assess parental smoking and the risk of respiratory symptoms among school boys in Al-Khobar City, the rate of smoking among parents was $18.2 \%$ (32\% among fathers and $4 \%$ for mothers) (Bassiony et al., 2009). Another study demonstrated that the prevalence of current smoking was higher among married people (Jarallah et al., 1999). Other studies showed that $50.6 \%$ and $45.8 \%$ of pregnant mothers were passive smokers (Rashid et al., 2003; Banoon et al., 2014). Compared to cigarette smoking, the prevalence of waterpipe (WP) smoking was slightly higher in Saudi Arabia (Akl et al., 2011). A high prevalence was demonstrated even in young age, where $12-30 \%$ and $37 \%$ of school children and university students were WP smokers, with an increasing prevalence among women of all ages (Neergaard et al., 2007).

With the high reported prevalence of smoking among Saudi population, there is limited information on levels of total cotinine in Saudi children exposed to SHS. This study aimed to assess the exposure of schoolchildren to SHS, and to measure urinary cotinine level as a biomarker of SHS in their urine.

\section{Materials and Methods}

A cross-sectional study was carried out on a sample of elementary schoolchildren aged 6-12 years in the time frame from January to April 2015.

\section{Study setting: primary schools in Taif City}

Sampling: Multistage cluster sampling methodology was carried out. Following simple random sampling technique, 4 schools ( 2 for girls and 2 for boys) were randomly chosen from all primary schools in Taif city. One class from each school grade (first to the 6th) was chosen following the same technique.

The total number of students enrolled in the selected classes in the academic year (2014 2015$)$ was 526 students (257 boys and 269 girls). Students from other nationalities, who were absent, didn't bring the written consent or refused sharing in the study, were excluded. After exclusion of the non-respondents, the response rate was $95.6 \%$ and a total of 503 students were the subjects of the study ( 246 boys and 257 girls).

\section{Ethical considerations}

Official approvals on the study were obtained from the ethics committee of scientific research of Taif University, and from the general director of basic education of Taif governorate. The selected schools received approval letters with permission from the general director of basic education to conduct the study. After explaining the aim of the study to the schools principals, the schools administrative offices sent official letters and questionnaires with consent forms to the students' parents/ guardians. The letter contained information on the aim and date of the study, and encouraging them for participation. Parents/guardians were asked to fill the questionnaire, and to sign the consent form for their children before sharing in the study.

The questionnaire included five questions asking about SHS exposure and smoking rules in the residence. The questions were as follows: 1) In the past month, how many packs of cigarettes did you smoke inside the home in the presence of the child; 2) Not including you, how many smokers who live with the child smoke inside his house. (If the answer was $\geq 1$ to either of these questions, the child was considered to be exposed to SHS) (Hecht et al., 2001). On average for the past month, what was the number of minutes or hours per week the child spent in a car, bus, van, or other enclosed vehicle with anyone who was smoking tobacco. 4) On average for the past month, what was the number of minutes or hours per week the child spent in any other indoor or enclosed location with anyone who was smoking tobacco? (Positive answers to these questions were taken to indicate exposure to SHS) (Hecht et al., 2001). Regarding smoking rules at the residence, the caregiver was asked to describe those rules. The response options included: (a) No one is allowed to smoke anywhere (b) Smoking is allowed in some places or at some times; (c) Smoking is allowed anywhere (there are no rules) (Hecht et al., 2001).

\section{Laboratory analysis}

Urine samples (15-20 mL) were obtained at schools under the supervision of the school health visitors and the researchers in 100-mL polypropylene containers. Urine was collected without preservation and after centrifugation. Samples were analyzed for total cotinine, where the research was done on the machine "IMMULITE" using chemiluminescent immunoassay method.

\section{Statistical methods}

Data was collected and entered to the computer using the statistical package for the social sciences

Table 1. Description of the Studied Group

\begin{tabular}{llcc}
\hline Parameter & & The studied group N $=503$ \\
\hline Age & $\mathrm{X} \pm \mathrm{SD}$ & \multicolumn{2}{c}{$8.67 \pm 1.86$} \\
& Range & \multicolumn{2}{c}{$6-12$} \\
\multirow{3}{*}{ Sex } & Mo & 46.1 \\
& Male & 232 & 53.9 \\
Grade & Female & 271 & 17.7 \\
& 1st grade & 89 & 19.1 \\
& 2nd grade & 96 & 18.3 \\
& 3rd grade & 92 & 17.5 \\
& 4th grade & 88 & 13.5 \\
\hline
\end{tabular}


Exposure to Environmental Tobacco Smoke and Cotinine in the Urine of School Children in Taif City, Saudi Arabia

Table 2. Descriptive Statistics of Smoking Exposure among the Studied Group

\begin{tabular}{|c|c|c|}
\hline \multirow[b]{2}{*}{ Parameter } & \multicolumn{2}{|c|}{ The studied group $\mathrm{N}=503$} \\
\hline & No & $\%$ \\
\hline \multicolumn{3}{|l|}{ Father smoking status } \\
\hline Smoker & 193 & 38.4 \\
\hline Non smoker & 310 & 61.6 \\
\hline \multicolumn{3}{|c|}{ Number of cigarette backs smoked in the last month: $N=193$} \\
\hline$\leq 10$ & 124 & 64.2 \\
\hline $11-20$ & 62 & 32.1 \\
\hline $21-30$ & 5 & 2.6 \\
\hline$>30$ & 2 & 1 \\
\hline \multicolumn{3}{|c|}{$\begin{array}{l}\text { Mean } \pm \text { SD of number of cigarette backs smoked by father in } \\
\text { the last month: } \quad \mathrm{N}=193\end{array}$} \\
\hline $\mathrm{X} \pm \mathrm{SD}$ & \multicolumn{2}{|c|}{$12.48 \pm 7.47$} \\
\hline Range & \multicolumn{2}{|c|}{$5-60$} \\
\hline \multicolumn{3}{|c|}{$\begin{array}{l}\text { Number of smokers other than father live with the child and } \\
\text { smoke inside his house: }\end{array}$} \\
\hline No one & \multicolumn{2}{|c|}{251} \\
\hline 1 & \multicolumn{2}{|l|}{194} \\
\hline 2 & \multicolumn{2}{|l|}{49} \\
\hline 3 and more & \multicolumn{2}{|l|}{9} \\
\hline \multicolumn{3}{|l|}{ Exposure of the child to SHS indoors } \\
\hline Non exposed & \multicolumn{2}{|l|}{192} \\
\hline Exposed & \multicolumn{2}{|c|}{311} \\
\hline \multicolumn{3}{|c|}{$\begin{array}{l}\text { Hours per week the child spent in any other indoor or enclosed } \\
\text { location with anyone who was smoking tobacco in the past week }\end{array}$} \\
\hline (Indoor exposure): & \multicolumn{2}{|c|}{$\mathrm{N}=311$} \\
\hline Less than 4 hours & \multicolumn{2}{|l|}{169} \\
\hline More than 4 hours & \multicolumn{2}{|c|}{142} \\
\hline \multicolumn{3}{|c|}{$\begin{array}{l}\text { Mean } \pm \text { SD of average hours per week the child spent in any } \\
\text { other indoor or enclosed location with anyone who was smoking } \\
\text { tobacco in the past month (Indoor exposure) } \mathrm{N}=311\end{array}$} \\
\hline $\mathrm{X} \pm \mathrm{SD}$ & \multicolumn{2}{|c|}{$6.76 \pm 6.10$} \\
\hline Range & \multicolumn{2}{|c|}{$1-25$} \\
\hline \multicolumn{3}{|l|}{ Exposure of the child to SHS outdoors } \\
\hline Non exposed & 296 & \\
\hline Exposed & 207 & \\
\hline Hours per week the child spent in a & losed veh & le with \\
\hline$<1$ hour & 114 & \\
\hline $1-2$ & 72 & \\
\hline$>2$ hours & 21 & \\
\hline $\begin{array}{l}\text { Average No. of hours per week the c } \\
\text { van, or other enclosed vehicle with an }\end{array}$ & $\begin{array}{l}\text { spent in a } \\
\text { who was }\end{array}$ & $\begin{array}{l}\text { ar, bus, } \\
\text { moking }\end{array}$ \\
\hline tobacco: & $\mathrm{N}=207$ & \\
\hline $\mathrm{X} \pm \mathrm{SD}$ & $1.46 \pm 0.7$ & \\
\hline Range & $0.5-5$ & \\
\hline Total exposure of children either indoc & outdoor $\mathrm{t}$ & SHS \\
\hline Non exposed & 156 & \\
\hline Exposed & 347 & \\
\hline Degree of exposure: & $\mathrm{N}=347$ & \\
\hline Double (indoor \& outdoor) & 171 & \\
\hline Single (indoor or outdoor) & 176 & \\
\hline Smoking rules at the residence & $\mathrm{N}=347$ & \\
\hline Smoking not allowed ever & 137 & \\
\hline Allowed in some places some times & 133 & \\
\hline Allowed any place any time & 77 & \\
\hline
\end{tabular}

(SPSS, version 20; IBM Corp., Armonk, New York, USA). Descriptive data was expressed as numbers and percentages, and quantitative data was expressed as mean and standard deviation (Mean \pm SD). Mann-Whitney, Kruskal-Wallis and Spearman correlation tests were used for non-parametric quantitative variables. A p-value of
$<0.05$ was considered as statistically significant.

\section{Results}

The study was carried out on 503 Saudi elementary schoolchildren, $53.9 \%$ were females and $46.1 \%$ were males with a mean age of $(8.67 \pm 1.86)$ years (Table 1$)$.

Of the participants, $38.4 \%$ had a smoking father, with $64.2 \%$ of fathers reported smoking $\leq 10$ packs in the last month. About $50 \%$ of the students with smoking father had no other smokers in the residence, where $48.3 \%$ reported having 1-2 smokers and $1.8 \%$ reported having $\geq 3$ smokers other than the father within the residence (Table 2).

The study showed that $61.8 \%$ of children reported exposure to SHS indoors with an average number of hours of exposure of $(6.76 \pm 6.10)$ /week. According to outdoor exposure, $41.2 \%$ of the studied group reported outdoor exposure with an average number of hours of exposure of $(1.46 \pm 0.72)$ /week. Either indoor or outdoor exposure

Table 3. Description of Cotinine Level among Different Exposures

\begin{tabular}{lcc}
\hline & Frequency & Cotinine level $(\mathrm{ng} / \mathrm{ml})$ \\
Parameter & No $(\%)$ & $\mathrm{X} \pm \mathrm{SD}$ \\
\hline Total (all sample) & $503(100)$ & $42.69 \pm 90.09$ \\
Non exposed & $156(31)$ & $7.32 \pm 4.54$ \\
All exposed & $347(69)$ & $58.60 \pm 104.64$ \\
Indoor & $140(27.8)$ & $11.09 \pm 9.24$ \\
Out door & $36(7.2)$ & $20.53 \pm 15.40$ \\
Double & $171(34.0)$ & $105.51 \pm 133.36$ \\
\hline
\end{tabular}

Table 4. Cotinine Level in Urine of Children Exposed to SHS Compared to Non-exposed

\begin{tabular}{lcc}
\hline & \multicolumn{2}{c}{ The studied group } \\
& Non exposed & Exposed \\
& $\mathrm{N}=156$ & $\mathrm{~N}=347$ \\
\hline Cotinine level & & \\
$\mathrm{X} \pm \mathrm{SD}(\mathrm{ng} / \mathrm{ml})$ & $7.32 \pm 4.54$ & $58.60 \pm 104.64$ \\
Range & $1-21$ & $1-614$ \\
\hline
\end{tabular}

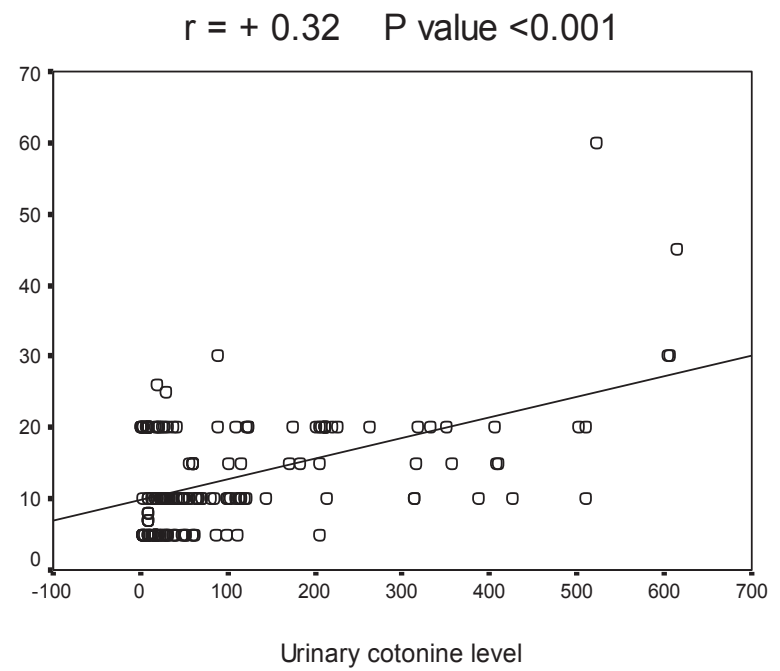

Figure 1. Correlation Between Urinary Cotinine Concentrations and the Number of Cigarette Packs Smoked by Parents 


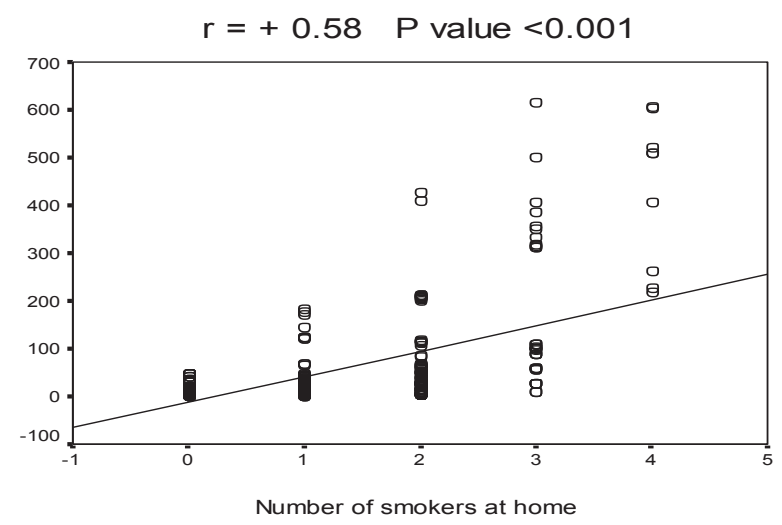

Figure 2. Correlation Between Urinary Cotinine Concentrations in Exposed Children and the Number of Smokers Inside House

Table 5. Cotinine Level with Double Exposure (indoor and outdoor) Compared to Single Exposure

\begin{tabular}{lcc}
\hline & \multicolumn{2}{c}{ Exposed group } \\
& $\begin{array}{c}\text { Single exposure } \\
\mathrm{N}=176\end{array}$ & $\begin{array}{c}\text { Double exposure } \\
\mathrm{N}=171\end{array}$ \\
\hline Cotinine level & & \\
$\mathrm{X} \pm \mathrm{SD}$ & $13.02 \pm 11.39$ & $105.51 \pm 133.36$ \\
Range & $1-49$ & $3-614$ \\
\hline
\end{tabular}

Table 6. Relationship between Urinary Cotinine Concentrations in Exposed Children and Smoking Rules at the Residence

\begin{tabular}{|c|c|c|}
\hline \multirow[b]{2}{*}{ Parameter } & \multicolumn{2}{|c|}{ Smoking rules among exposed group } \\
\hline & $\begin{array}{l}\text { Smoking not } \\
\text { allowed ever } \\
\mathrm{N}=137\end{array}$ & $\begin{array}{l}\text { Allowed in some } \\
\text { places some times } \\
\qquad \mathrm{N}=133\end{array}$ \\
\hline \multicolumn{3}{|c|}{ Cotinine level } \\
\hline $\mathrm{X} \pm \mathrm{SD}$ & $15.22 \pm 10.63$ & $53.23 \pm 82.38$ \\
\hline Range & $1-47$ & $2-426$ \\
\hline
\end{tabular}

was reported in $69 \%$ of children, with an overall $49.3 \%$ of children reported double exposure (both indoor and outdoor).

As regards application of smoking rules at residence, $39.5 \%$ of the exposed group reported complete restriction of smoking at the residence, $38.3 \%$ reported that smoking is allowed in some times and some places, and $22 \%$ reported that there are no restrictions on smoking in the residence at all.

(Table 4) shows that the mean urinary cotinine was significantly higher among children exposed to SHS compared to unexposed children $(58.60 \pm 104.64 \mathrm{ng} / \mathrm{ml}$ vs $7.32 \pm 4.54 \mathrm{ng} / \mathrm{ml})(\mathrm{p}$-value $=<0.001)$. Urinary cotinine level in children with double exposure to SHS (both indoor and outdoor) was significantly higher when compared with urinary cotinine level in children with single exposure (either indoor or outdoor) (Table 5).

A significant positive correlation was found between urinary cotinine concentrations and the number of cigarette packs smoked by parents $(\mathrm{r}=0.32$, $\mathrm{p}$-value $=<0.001)$ (Figure
1). And a significant positive correlation was also found between urinary cotinine concentrations and the number of smokers in the residence $(\mathrm{r}=0.58, \mathrm{p}$-value $=<0.001)$ (Figure2).

According to smoking rules at the residence of exposed children, the mean urinary cotinine level was significantly higher in children who reported no smoking rules at the residence, when compared with the mean urinary cotinine in children with residences where smoking was not allowed ever or where smoking rules were partially applied (Table 6).

\section{Discussion}

The present study was a cross-sectional study carried out on a sample of 503 Saudi elementary school children to assess their exposure to SHS and their urinary cotinine level. The study showed that $38.4 \%$ of fathers of the studied children were smokers. This figure that is somewhat higher than that reported in a previous Saudi study carried out in in Al-Khobar City, where 32\% of fathers were smokers (Bassiony et al., 2009). And it is lower than that reported from a Turkish study where $60.6 \%$ of fathers were smokers (Boyaci et al., 2006). However, the reported prevalence is consistent with the high reported prevalence of current smoking among Saudi population (Bassiony et al., 2009).

The present study revealed that $61.8 \%$ of children were exposed to indoor SHS. This figure is higher than that reported from a study done in USA on pre-school children, where $38 \%$ of children were exposed to SHS at home. It is also higher that that reported from the UK (50\%) and Northern European countries (57\%) (Gergen et al., 1998; Lund et al., 1998; Jarvis et al., 2000). This difference could be attributed to the reported high prevalence of smoking among Saudi population (Bassiony et al., 2009; WHO, 2013), not only among adults, but also among young ages. A national study conducted in 2008 reported a smoking prevalence of $36 \%$ and $3 \%$ among male and female adults, respectively (Albedah et al., 2011). And in a study done in Jeddah in 2015, the prevalence of ever tobacco use among Saudi female school adolescents was $44.2 \%$ (36.2\% water pipe and $30.9 \%$ cigarettes) (AlOtaibi et al., 2015). Another study done in Al-Hassa on secondary school students found a prevalence of $30.3 \%$ among males and $8.5 \%$ in females, where WP was used by $53.9 \%$ of the current tobacco users (Amin et al., 2010). The high prevalence of WP smoking among Saudi population could also be palmed for the reported high exposure. In a previous study carried out on 1272 high school students in Riyadh city, the prevalence of WP smoking among the parents was $10.5 \%$, the prevalence of other WP smokers at home was $18.2 \%$, and half of WP female smokers reported smoking inside their homes (Moamary et al., 2012).

In Taif city, the same high prevalence of smoking was reported. A study carried out on 2514 secondary school male students revealed that the prevalence of $\mathrm{f}$ tobacco smoking was $35.25 \%$ (Isa et al., 2014). Another study done on university students found a prevalence of $20 \%(29.4 \%$ among males and $11.4 \%$ among females) (Mansour et al., 2015). The reported high indoor exposure to SHS in 
the present study could be attributed to being an urban area in Taif city. Population density is always higher in the urban areas, which lead to higher probability of SHS exposure as housing is mainly represented by apartment buildings (Stepanov et al., 2006). In addition, Taif city lies in Mecca Province in Saudi Arabia, which is a region with a high concentration of Saudi population (Salam et al., 2014), and a high number of households (Abdul Salam, 2013). However, the reported indoor exposure to SHS in the present study is lower than that reported from turkey (75\%) (Karadag et al., 2003).

In the present study, $48.3 \%$ of students with smoking father reported having 1-2 smokers in the residence, where $1.8 \%$ reported having 3 and more. This result is somewhat in agreement with a previous Saudi study carried out on university students, where $41.4 \%$ of current smokers were living in homes where others smoke (Al-Mohamed et al., 2010). It is also going with the previous Turkish study where a third smoker was present in the house in $2.1 \%$ of children (Boyaci et al., 2006).

The present study showed that $49.3 \%$ of children reported double exposure to SHS (both indoor and outdoor). This figure is higher than that revealed from a previous study carried out in Al- Madinah city, where the prevalence of SHS exposure was $32.7 \% 49.3 \%$, and $25 \%$ inside, outside, and both inside and outside the home, respectively ( Al-Zalabani et al., 2015).

And it is higher than that reported from a study done in Riyadh city, where the prevalence recorded was $27.9 \%$ for exposure at home and $38.2 \%$ for exposure outside household (Al-Bedah et al., 2010). However it is going with a regional report, where exposure to SHS was $38 \%$ inside homes and $46 \%$ in public places (Warren et al., 2009). It is also going on with a report which revealed the seriousness of the problem of exposure of Saudi children to SHS. This reports was issued from the Global youth tobacco survey (GYTS) carried out in Saudi Arabia. The report showed that 3 in 10 students live in homes where others smoke in their presence, over 4 in 10 are exposed to smoke in public places, 2 in 10 have parents who smoke (CDC, 2006).

An explanation for this high exposure of children in the present study to SHS, could be the different locations and the higher population density in Taif city. In addition to inclusion of younger age group in our study compared to intermediate and secondary school students in Al-Madinah and Riyadh cities. of children have a high vulnerability to exposure to SHS involuntarily, as they have limited options for avoiding exposure to SHS, and depend on their parents and on adults around them for protection (U.S. Department of Health and Human Services, 2007). Added to this is the nature of children as they often sit closer to their parents, family members, or caregivers which make them closer to the source of pollutants than other passive smokers (Abou El-Ellaa et al., 2014).

The present study showed that the mean urinary cotinine level in the students exposed to SHS was significantly higher than the mean value in the un-exposed children (Table 3). This result is in agreement with previous studies (Hecht et al., 2001; Seifert et al., 2002; Boyaci et al., 2006; Stepanov et al., 2006; Goniewicz et al., 2011; Vogel et al., 2011; Abou El-Ellaa et al., 2014). Based on urinary cotinine level, the present study showed that even in children who were classified as un-exposed to SHS, cotinine was detected in their urine. This result was found in a previous study, where $75.6 \%$ of the studied children who were classified as un-exposed to SHS had measurable cotinine levels (Mannino et al., 2001), a finding that was demonstrated also in other studies (Hecht et al., 2001; Bono et al., 2005). This was explained partially by the inadequate reporting, and partially by parental unawareness with the possible SHS exposure outside the child's home.

It is known that home is the major exposure site for children to SHS, however locations outside home may also contribute to SHS exposure. For example, vehicles are a significant source of SHS exposure for children; they can be regularly exposed to SHS when parents or other adults smoke inside it in their presence. The concentrations of SHS in vehicles where smoking is occurring can reach very high levels (CDC, 2006). In the present study, urinary cotinine level in children with double exposure to SHS (both indoor and outdoor) was significantly higher when compared with urinary cotinine level in children with single exposure (Table 4). This result is going with those revealed from a previous study which showed that the total cotinine increased 2- to 3-fold when both kinds of exposure were reported (Preston et al., 1997). The significant positive correlation found between urinary cotinine concentrations and the number of cigarette packs smoked by father in the present work (Figure 1), is consistent with results revealed from previous studies. These studies revealed the same positive correlation between the reported amount of smoking and the levels of urinary cotinine (Seifert et al., 2002; Kim et al., 2004; CDC, 2006; Olivieri et al., 2006; Reeves et al., 2008; Schvartsman et al., 2013; Abou El-Ellaa et al., 2014). Regarding the number of smokers in the residence, a significant positive correlation was found between urinary cotinine concentrations and the number of smokers in the residence (Figure2). This is in agreement with other studies which revealed that cotinine levels in children are dose dependent, and is positively correlated with the number of smokers in the home (Seifert et al., 2002). This finding is consistent with another study where urinary cotinine levels were found to increase by 5 times depending on the number of smoking parents ( 1 or 2 smokers) (Jurado et al., 2004).

In this study, urinary cotinine level was significantly higher in children with reported no smoking rules at the residence, compared with urinary cotinine level in children with residences where smoking was not allowed ever or where smoking rules were partially applied (Table 6). This result is in agreement with previous studies which showed that Children who live in homes where smoking is allowed have higher levels of cotinine (CDC, 2006; CDC, 2005).

A limitation of this study was the usage of a selfreported questionnaire to collect data about smoking patterns and the amounts of tobacco smoked, which was prone to recall bias. Another limitation was the absence of any laboratory in the kingdom having a facility to carry out the assessment of cotinine level in urine. That is why all 
samples were sent to Germany which was time consuming.

In Conclusion, This study revealed that exposure of Saudi children to SHS is very high, although Saudi Arabia is considered as one of the pioneer tobacco control countries in the Eastern Mediterranean Region. The study calls for the importance of antismoking media awareness campaign on the harmful effects of SHS. Family counseling programs targeted to parents should be done to promote smoke-free homes, and increase parents' awareness about the hazards of SHS and the importance to quit smoking for the benefit of their children. The study indicates the necessity of adopting smoke-free policies and bans on smoking in vehicles and public places or any other facilities where a child is present. Strengthening the role of mosques in raising the awareness of families on the religion's stance on smoking and its harmful effects should be taken in consideration in this religious country.

\section{Acknowledgements}

The authors gratefully acknowledge the financial support provided by Taif University, (Grant number: 3676-435-1). We appreciate the cooperation of the school authorities, parents and children of the surveyed schools.

\section{References}

Abdul Salam A (2013). Population and Household Census, Kingdom of Saudi Arabia 2010: Facts and Figures. Center for Population Studies King Saud University Riyadh, Saudi Arabia. Int J Humanit Soc Sci, 3, 258-63

Abou El-Ellaa SS, Tawfika MA, El Bassuonib MA, Yahiaa MI (2014). Urinary cotinine level in passive smoker nondiabetic children of diabetic families. Menoufia Medical Journal, 27, 23-27

Akl EA, Gunukula SK, Aleem S, et al (2011). The prevalence of waterpipe tobacco smoking among the general and specific populations: a systematic review. BMC Public Health, 11, 244-56

Al Moamary MS1, Al Ghobain MA, Al Shehri SN, et al (2012). The prevalence and characteristics of water-pipe smoking among high school students in Saudi Arabia.J Infect Public Health, 5, 159-68

Albedah AM, Khalil MK, Khalil AA, Elolemy AT (2011). Use of the target group index survey to evaluate the cigarette smoking profile in Saudi Arabia. Saudi Med J, 32, 1055-9

Al-Bedah AM, Qureshi NA, Al-Guhaimani HI, Basahi JA(2010). The Global Youth Tobacco Survey - 2007: comparison with the global youth tobacco survey 2001-2002 in Saudi Arabia. Saudi Med J, 31, 1036-43

Al-Mohamed HI, Amin TT (2010). Pattern and prevalence of smoking among students at King Faisal University, Al Hassa, Saudi Arabia. EMHJ, 16, 56-64

Al-Otaibi AA, Ibrahim FB, Rampal L, Hassan SA, Normala Ibrahim N (2015). Prevalence of Tobacco Use and its Sociodemographic Determinants among Saudi Female School Adolescents in Jeddah. Malaysian Journal of Medicine and Health Sciences, 11, 39-48

Al-Zalabani A H, Amer SM, Kasim KA, Alqabshawi RI, Abdallah AR (2015). Second-hand smoking among intermediate and secondary school students in madinah, Saudi Arabia. Biomed Res Int, 15, 17-24

Amin TT, Amr MAM, Zaza BO, Suleman W (2010). Harm perception, attitudes and predictors of waterpipe (shisha) smoking among secondary school adolescents in al- hassa, Saudi Arabia. Asian Pacific J Cancer Prev, 11, 293-301

Banoon SK (2014). Environmental tobacco smoke (ETS) among pregnant women visiting primary health care (PHC) in Makah. International Journal of Medical Science and Public Health, 3, 672-8

Bassiony M (2009). Smoking in Saudi Arabia. Saudi Med J, 30, 876-81.

Bernert JT, Pirkle JL, Xia Y, et al (2010). Urine concentrations of a tobaccospecific nitrosamine carcinogen in the U.S. population from secondhand smoke exposure. Cancer Epidemiol Biomarkers \& Prev, 19, 2969-77.

Bono R1, Vincenti M, Schilirò T, et al (2005). Cotinine and $\mathrm{N}$-(2-hydroxyethyl)valine as markers of passive exposure to tobacco smoke in children. J Expo Anal Environ Epidemiol, 15, $66-73$.

Boyaci H, Etiler N, Duman C, Basyigit I, Pala A (2006). Environmental tobacco smoke exposure in school children: parent report and urine cotinine measures. Pediatrics International, 48, 382-9.

Centers for Disease Control and Prevention (2005) Third national report on human exposure to environmental chemicals. Atlanta: U.S. Department of Health and Human Services, Centers for Disease Control and Prevention, National Center for Environmental Health. NCEH. Publication No. 05-0570

Centers for Disease Control and Prevention (CDC). Smoking \& Tobacco Use: Health Effects of Secondhand Smoke. Atlanta: U.S. Department of Health and Human Services, Centers for Disease Control and Prevention, National Center for Chronic Disease Prevention and Health Promotion, Office on Smoking and Health. ttp://www.cdc.gov/tobacco/data_ statistics/fact_sheets/secondhand_smoke/health_effects

Centre for disease control and prevention (CDC) (2006): Use of cigarettes and other tobacco products among students aged 13-15 years worldwide 1999-2005. MMWR Morb mortal Wkly Rep, 55, 553-6

Gergen PJ, Fowler JA, Maurer KR, Davis WW, Overpeck MD (1998). The burden of environmental tobacco smoke exposure on the respiratory health of children 2 months through 5 years of age in the United States: Third National Health and Nutrition Examination Survey, 1988 to 1994. Pediatrics, 101, 8

Goniewicz ML, Eisner MD, Eduardo L, et al (2011). Comparison of urine cotinine and the tobacco-specific nitrosamine metabolite 4-(Methylnitrosamino)-1-(3-Pyridyl)-1-Butanol (NNAL) and Their Ratio to Discriminate Active From Passive Smoking. Nicotine Tob Res, 13, 202-8

Hecht SS, Ye M, Carmella SG, et al (2001). Metabolites of a tobacco-specific lung carcinogen in the urine of Elementary School-aged Children. Cancer Epidemiol Biomarkers Prev, 10, 1109-16.

Isa MM, El-Sabbagh OI (2014). Alert Addiction among Young Students in Taif City in Western Area of Saudi Arabia. International Journal of Scientific and Research Publications, 4, 2250-3153

Jarallah J, Al-Rubeaan K, Al-Nuaim AR,Al-Ruhaily A, Kalantan K (1999). Prevalence and determinants of smoking in three regions of Saudi Arabia. Tob Control, 8, 53-56.

Jarvis MJ, Goddard E, Higgins V, et al (2000). Children's exposure to passive smoking in England since the 1980s: cotinine evidence from population surveys. BMJ, 321, 343-5.

Jurado D, Muñoz C, Luna Jde D, Fernández-Crehuet M (2004). Environmental tobacco smoke exposure in children: parental perception of smokiness at home and other factors associated with urinary cotinine in preschool children. $J$ Expo Anal Environ Epidemiol, 14, 330-6.

Karadag B, Karakoc F, Ceran O, et al (2003). Does passive smoke 
Exposure to Environmental Tobacco Smoke and Cotinine in the Urine of School Children in Taif City, Saudi Arabia

exposure trigger acute asthma attack in children?. Allergol Immunopathol, 31, 318-23

Kim HI, Lim Y, Lee S, et al (2004). Relationship between environmental tobacco smoke and urinary cotinine levels in passive smokers at their residence. J Expo Anal Environ Epidemiol, 14, 65-70.

Lando HA, Hipple BJ, Muramoto M, et al (2010). Tobacco is a global pediatric concern. Bull World Health Organ, 88, $2-2$.

Lund KE, Skrondal A, Vertio H, Helgason AR (1998). To what extent do parents strive to protect their children from environmental tobacco smoke in the Nordic countries? A population-based study. Tob Control, 7, 56-60 .

Mannino DM1, Caraballo R, Benowitz N, Repace J (2001). Predictors of cotinine levels in US children: data from the third national health and nutrition examination survey. Chest, 120, 718-24.

Mansour MAM, Youssef HAM, Al-Mawajdeh NA, Ayasreh I (2015). Awareness, attitude and practice of smoking among medical sciences\& non-medical sciences students at Taif university: comparative study. International Journal of Science and Research, 4, 255-64

Martins-Green M,Adhami N, Frankos M, et al (2014). Cigarette smoke toxins deposited on surfaces: implications for human health. PLOS ONE, 9, 86391

Neergaard J, Singh P, Job J, Montgomery S (2007). Waterpipe smoking and nicotine exposure: a review of the current evidence. Nicotine Tob Res, 9, 987-94.

Öberg M, Jaakkola MS, Prüss-Üstün A, Schweizer C, Woodward A (2010). Second-hand smoke: Assessing the burden of disease at national and local levels. Tobacco free initiative, public health and the environment, Geneva. European Centre for Environment and Health, Rome. Environmental Burden of Disease Series, No. 18. http://www.who.int/ quantifying_ehimpacts/publications/SHS.pdf

Olivieri M1, Bodini A, Peroni DG, et al (2006). Passive smoking in asthmatic children: Effect of a 'smoke-free house' measured by urinary cotinine levels. Allergy Asthma Proc, 27, 350-3.

Preston AM1, Ramos LJ, Calderon C, Sahai H (1997). Exposure of Puerto Rican children to environmental tobacco smoke. Prev Med, 26, 1-7.

Rashid M, Rashid H (2003). Passive maternal smoking and pregnancy outcome in a Saudi population. Saudi Med J, 3, 248-53.

Reeves S, Bernstein I (2008). Effects of maternal tobacco-smoke exposure on fetal growth and neonatal size. Expert Rev Obstet Gynecol, 3, 719-30

Salam AA, Elsegaey I, Khraif R, Al-Mutairi RA (2014). Population distribution and household conditions in Saudi Arabia: reflections from the 2010 Census. Center for Population Studies, King Saud University, Riyadh, Saudi Arabia. SpringerPlus, 3, 530

Salim EI1, Jazieh AR, Moore MA(2011). Lung cancer incidence in the arab league countries: risk factors and control. Asian Pac J Cancer Prev, 12, 17-34

Schvartsman C, Farhat SCL, Schvartsman S, Saldiva PHN (2013). Parental smoking patterns and their association with wheezing in children. Clinics (Sao Paulo), 68, 934-9.

Seifert JA, Ross CA, Norris JM (2002). Validation of a fivequestion survey to assess a child's exposure to environmental tobacco smoke. Ann Epidemiol, 12, 273-7.

Shenkin JD, Broffitt B, Levy SM, Warren JJ (2004). The assotiation between environmental tobacco smoke and primary tooth caries. J Public Health Dent, 64, 184-6.

Stepanov I, Hecht SS, Duca G, Mardari I (2006). Uptake of the tobacco-specific lung carcinogen 4-(methylnitrosamino)1-(3-pyridyl)-1-butanone by moldovan children. Cancer
Epidemiol Biomarkers Prev, 15, 7-11

Stošić1 L, Nikić D, Nikolić M, Milutinović S, Stanković A (2006). Determination of environmental tobacco smoking in schoolchildren with urine cotinine measurements. Medicine and Biology, 13, 119-22.

Thomas JL, Guo H, Carmella SG, et al (2011). Metabolites of a tobacco-specific lung carcinogen in children exposed to secondhand or thirdhand tobacco smoke in their homes. Cancer Epidemiol Biomarkers Prev, 20, 1213-21.

Tutka P, Wielosz M, Zatonski W (2002). Exposure to environmental tobacco smoke and children health. Int $J$ Occup Med Environ Health, 15, 325-35.

U.S. Department of Health and Human Services (2006). The Health consequences of involuntary exposure to tobacco smoke: a report of the surgeon general. Washington, D.C.: U.S. Department of Health and Human Services, Public Health Service, Centers for Disease Control, Center for Health Promotion and Education, Office on Smoking and Health.

U.S. Department of Health and Human Services (2007). Children and secondhand smoke exposure, the health consequences of involuntary exposure to tobacco smoke: A Report of the Surgeon General. Atlanta, GA: U.S. Department of health and human services, centers for disease control and prevention, coordinating center for health promotion, national center for chronic disease prevention and health promotion, office on smoking and health.

U.S. Food and Drug Administration (2012). Guidance, regulation, \& compliance: harmful and potentially harmful constituents in tobacco products and tobacco smoke: established list. USDA.GOV. http://www.fda.gov/ TobaccoProducts/ GuidanceComplianceRegulatoryInformation/ucm297741.

Vineis P, Airoldi L, Veglia F, et al (2005). Environmental tobacco smoke and risk of respiratory cancer and chronic obstructive pulmonary disease in former smokers and never smokers in the EPIC prospective study. $B M J, 330,277-82$.

Vogel RI, Carmella SG, Stepanov I, Hatsukami DK, Hecht SS (2011). The ratio of a urinary tobacco-specific lung carcinogen metabolite to cotinine is significantly higher in passive than in active smokers. Biomarkers, 16,491-7

Warren CW, Asma S, Lee J, Lea V, Mackay J (2009). Global tobacco surveillance system: The GTSS Atlas.

World Health Organization (2011). Report on the global tobacco epidemic: country profile Saudi Arabia; 2011. http://www. who.int/tobacco/

World Health Organization (2013). WHO report on the Global Tobacco Epidemic, 2013, Country profile, Saudi Arabia. http://www.who.int/tobacco/surveillance/policy/country_ profile/sau.pdf 